
репарации у пациентов с первым эпизодом шизофрении при терапии антипсихотиками. Сибирский вестник психиатрии и наркологии. 2020; 4 (109): 15-20. https://doi.org/10.26617/1810-3111-2020-4(109)-15-20

\title{
Изменение некоторых показателей нейрорепарации у пациентов с первым эпизодом шизофрении при терапии антипсихотиками
}

\author{
Сахаров А.В.', Мындускин И.В., ${ }^{1}$, Терешков П.П.' \\ ${ }^{1}$ ФГБОУ ВО «Читинская государственная медицинская академия» Минздрава России \\ Россия, 672000, Чита, ул. Горького, 39-а \\ ${ }^{2}$ ГКУЗ «Краевая клиническая психиатрическая больница им. В.Х. Кандинского» \\ Россия, 672042, Чита, Окружной проезд, 3
}

\begin{abstract}
PEЗЮME
Введение. В настоящее время не вызывает сомнений факт существенной роли процессов нейродеструкции и нейрорепарации в механизмах развития психических расстройств, в том числе шизофрении. При этом многие нейротрофные факторы остаются неисследованными при данном заболевании, в том числе их динамика на фоне антипсихотической терапии. Цель: изучение некоторых показателей нейрорепарации у пациентов с первым эпизодом шизофрении при терапии антипсихотиками первого и второго поколений. Материалы и методы. Обследовано 40 пациентов с диагнозом «шизофрения параноидная, период наблюдения менее года» (F20.09), обследование проведено дважды: до начала лечения нейролептиками и через 4 недели психофармакотерапии. Пациенты первой группы получали галоперидол, второй группы - рисперидон. Группу контроля составили 20 здоровых добровольцев. Определение показателей нейромаркеров проводили в сыворотке крови методом проточной флюориметрии. Результаты. Уровень мозгового нейротрофического фактора был сниженным и постепенно увеличивался до контрольных значений в процессе лечения, отличий в зависимости от вида антипсихотика установлено не было. Содержание фактора роста нервов и васкулоэндотелиального фактора роста существенно увеличивалось при терапии галоперидолом, а фракталкина - при терапии рисперидоном. Таким образом, установлено повышение уровня всех исследуемых показателей нейрорепарации у пациентов с первым эпизодом шизофрении, что свидетельствует о раннем включении защитных нейропротективных механизмов при терапии антипсихотиками.
\end{abstract}

Ключевые слова: параноидная шизофрения, антипсихотики, нейрорепарация, фактор роста нервов, мозговой нейротрофический фактор, фракталкин, васкулоэндотелиальный фактор роста.

\section{ВВЕДЕНИЕ}

Уже давно установлено - в развитии шизофрении существенную роль играют процессы нейродеструкции, связанные с активацией аутоиммунных механизмов болезни и повышением проницаемости гематоэнцефалического барьера, что ведет к появлению в крови мозгоспецифических белков - маркеров повреждения нервной ткани. Нейровоспаление в основном опосредуется провоспалительными цитокинами и нейроглией. В отличие от периферических воспалительных реакций, нейровоспаление участвует в различных функциях нейронов, в том числе и в нейрогенезе $[1,2]$. Поэтому нейродеструкции, как правило, сопутствует нейрорепарация.

Нейрорепарация - естественный процесс, подразумевающий постоянство правильной экспрессии ДНК и сохранение нормального фенотипа нервной клетки. В течение длительного времени считалось, что нейроны не способны к регенера- ции. Более поздние исследования доказали, что возможна не только внутриклеточная регенерация нейронов, но и дифференцировка новых клеток из предшественников (нейрогенез) [2, 3]. При этом нейрорепарации может способствовать большое количество факторов.

Первым идентифицированным нейротрофным фактором и родоначальником этой особой по своей биологической активности группы белков стал фактор роста нервов (NGF). Еще одним хорошо изученным нейротрофином является мозговой нейротрофический фактор (BDNF). Оба данных фактора роста близки по своей структуре, синтезируются в развивающемся организме клеткоймишенью, диффундируют по направлению к нейрону и связываются с молекулами рецепторов на его поверхности, что приводит к активному росту аксона. В результате аксон достигает клетки-мишени, устанавливая с ней синаптический контакт [3]. 
Указанные нейротрофины у взрослого человека способствуют восстановлению нейронов и аксонов, миелиновой оболочки, формированию новых связей $[4,5,6]$.

Значимым фактором, усиливающим нейрогенез, является хемокин CX3CL1 или фракталкин $[7,8]$. Этот небольшой по размеру белок относится к цитокинам, сочетает в себе свойства хемоаттрактантов и молекул клеточной адгезии. Связываясь со специфическим рецептором в центральной нервной системе, CX3CL1 регулирует взаимодействия между нейронами, микроглией и иммунными клетками [9]. Предполагается, что данный хемокин может играть важную роль как в нейрогенезе, так и при патологических состояниях, например, при болезни Альцгеймера [8].

Другим существенным фактором, участвующим в нейрорепарации, считается сосудистый эндотелиальный фактор роста (VEGF). Этот гомодимерный дисульфидсвязанный гликопротеин способствует росту эндотелия и представляет собой важный фактор для ангиогенеза и васкуляризации [10]. Он оказывает нейротрофическое и нейропротекторное действие на шванновские клетки, микроглию, астроциты и нейроны [11].

Ряд из представленных показателей нейрорепарации уже изучались у пациентов с шизофренией. Получены противоречивые данные по динамике изменения содержания в сыворотке крови мозгового нейротрофического фактора при антипсихотической терапии [12]. Подтвержденным фактом является его пониженная концентрация у больных до лечения $[13,14,15]$. В немногочисленных публикациях установлено изначально пониженное содержание в крови у пациентов с шизофренией фактора роста нервов [16]. Совсем недавно стал исследоваться фракталкин при шизофрении. Так, S.L. Hill et al. (2020) установили в посмертных образцах мозга больных шизофренией дефицит этого белка [17]. Высказывается мнение о недооцененной роли микроглиального хемокина CX3CL1 в механизмах течения шизофрении [18]. В доступной литературе нам не встретилось публикаций, посвященных изучению содержания сосудистого эндотелиального фактора роста при шизофреническом процессе. При этом следует отметить, что в ряде проведенных исследований было выявлено, что антипсихотики как первого, так и второго поколения обладают способностью уменьшать уровень маркеров нейродеструкции головного мозга и улучшать защитно-компенсаторные процессы, направленные на восстановление нейропластичности, которая приводит к нейрорепарации $[5,12$, 19]. Поэтому интересным является исследование влияния разных антипсихотиков на содержание нейротрофических факторов, что в перспективе может иметь серьезное практическое значение.
Кроме того, детальное функционирование системы «нейродеструкция - нейрорепарация» у пациентов с первым психотическим эпизодом изучено недостаточно, а роль большинства из представленных выше факторов нейрогенеза при шизофрении полностью не исследована.

\section{ЦЕЛЬ ИССЛЕДОВАНИЯ}

Изучение некоторых показателей нейрорепарации у пациентов с первым эпизодом шизофрении при терапии антипсихотиками первого и второго поколений.

\section{МАТЕРИАЛЫ И МЕТОДЫ}

На базе ГКУЗ «Краевая клиническая психиатрическая больница имени В.Х. Кандинского» было обследовано 40 пациентов с диагнозом «шизофрения параноидная, период наблюдения менее года» (шифр по МКБ-10 F20.09). Возраст обследованных пациентов находился в диапазоне от 18 до 35 лет. Возрастные ограничения введены, чтобы не включать в исследование юношеские варианты шизофрении и позднюю шизофрению, которые имеют характерные особенности клиники и течения, и исключить возрастное патопластическое влияние на лабораторные показатели.

В течение 4 недель пациенты находились на стационарном лечении. Все пациенты методом простой рандомизации были разделены на две группы. 1-я группа - 20 больных, принимавших антипсихотик первого поколения галоперидол; 2-я группа - 20 больных, которые принимали антипсихотик второго поколения рисперидон.

Доза галоперидола варьировала от 10 до 20 мг в сутки, средняя суточная доза составила $13,6 \pm 0,7$ мг. При возникновении экстрапирамидных расстройств в схему лечения включался тригексефенидил, средняя суточная доза которого составляла 4,3 $\pm 0,2$ мг. Суточная доза рисперидона была в диапазоне от 4 до 8 мг, средняя суточная доза

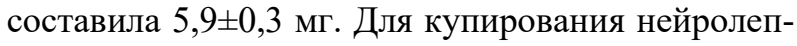
тического синдрома использовался тригексефенидил в средней суточной дозе $3,6 \pm 0,2$ мг.

Больные на момент включения в исследование находились в остром психотическом состоянии. Общий балл по Шкале позитивных и негативных симптомов (The Positive and Negative Syndrome Scale, PANSS) составил 107,5 [103,5; 114,0], в группе получающих галоперидол - 108 [101; $113,5]$, в группе получающих рисперидон - 106 [104; 116]. Забор крови для исследований проводился дважды: в 1-й день поступления (до лечения) и через 4 недели от госпитализации и начала лечения антипсихотиками.

Критерии исключения из исследования: возраст младше 18 лет и старше 35 лет, потребление наркотических веществ и злоупотребление алкоголем, наличие воспалительных заболеваний любой этиологии (острых, хронических в стадии 
обострения), наличие другой патологии центральной нервной системы, беременные и лактирующие женщины.

Контрольную группу составили 20 психически и соматически здоровых людей. От всех вклю- ченных в исследование получено добровольное информированное согласие на участие в исследовании. Обследованные лица были полностью сопоставимы между собой по полу и возрасту $\mathrm{p}>0,05$ (табл. 1).

Т а б л и ц а 1. Половозрастные характеристики обследованных пациентов с острой шизофренией

\begin{tabular}{|l|c|c|c|}
\hline \multicolumn{1}{|c|}{ Показатель } & $\begin{array}{c}\text { Группа контроля } \\
(\mathrm{n}=20)\end{array}$ & \begin{tabular}{c} 
Шизофрения параноидная, период наблюдения менее года (F20.09) \\
\cline { 3 - 4 }
\end{tabular} & $\begin{array}{c}\text { лечение галоперидолом } \\
\text { 2-я группа (n=20) - } \\
\text { лечение рисперидоном }\end{array}$ \\
\hline Пол (\%): & 40,0 & 50,0 & 45,0 \\
мужской & 60,0 & 50,0 & 55,0 \\
женский & $26,7 \pm 0,8$ & $27,9 \pm 1,0$ & $26,3 \pm 1,2$ \\
\hline Средний возраст (лет) & \multicolumn{2}{|r}{} \\
\hline
\end{tabular}

Лабораторная часть исследования осуществлялась в лаборатории клинической и экспериментальной биохимии и иммунологии НИИ молекулярной медицины ФГБОУ ВО «Читинская государственная медицинская академия» Минздрава России. Определение показателей нейромаркеров проводили в сыворотке крови методом проточной флюориметрии на проточном цитометре СуtoFLEX (Beckman Coulter, США) с использованием тест-системы LEGENDplex TM Human Neuroinflammation Panel 1 (13-plex) (BioLegend, США) согласно инструкции производителя. Исследовались $\beta$-NGF (фактор роста нервов), BDNF (мозговой нейротрофический фактор), хемокин CX3CL1 (фракталкин) и VEGF (васкулоэндотелиальный фактор роста). Полученные результаты выражали в пг/мл.
Статистическая обработка полученных результатов осуществлялась с применением пакета анализа Microsoft Excel 2016 и пакета прикладных статистических программ «Statistica-12». Данные представлены в виде медианы (Me) и интерквартильного (25-й и 75-й перцентили) интервала. Для сравнения двух независимых выборочных совокупностей применялся непараметрический Uкритерий Манна-Уитни. Для сравнения связанных между собой показателей (одна группа в динамике) использовался непараметрический Wкритерий Вилкоксона. Различия считали достоверными при показателе $\mathrm{p}<0,05$.

\section{РЕЗУЛЬТАТЫ И ОБСУЖДЕНИЕ}

Полученные данные по содержанию в плазме крови изучаемых маркеров системы нейрорепарации представлены в таблице 2.

T а б л и ц а 2. Показатели маркеров нейрорепарации у здоровых и пациентов с острой шизофренией

\begin{tabular}{|c|c|c|c|c|c|}
\hline \multirow{3}{*}{$\begin{array}{c}\text { Показа- } \\
\text { тель } \\
\text { (пг/мл) }\end{array}$} & \multirow{3}{*}{$\begin{array}{l}\text { Группа кон- } \\
\text { троля }(\mathrm{n}=20)\end{array}$} & \multicolumn{4}{|c|}{ Шизофрения параноидная, период наблюдения менее года (F20.09) } \\
\hline & & \multicolumn{2}{|c|}{ 1-я группа $(\mathrm{n}=20)$ - терапия галоперидолом } & \multicolumn{2}{|c|}{ 2-я группа (n=20) - терапия рисперидоном } \\
\hline & & до лечения & через 4 недели & до лечения & через 4 недели \\
\hline$\beta$-NGF & $\begin{array}{c}14,81 \\
(14,38 ; 22,76)\end{array}$ & $\begin{array}{c}14,93 \\
(13,74 ; 27,88) \\
0,2299 ; p^{1}=0,8181\end{array}$ & $\begin{array}{c}27,59(17,58 ; 39,87) \\
\mathbf{3 , 1 9 1 9 ;} \mathbf{p}^{\mathbf{1}}=\mathbf{0 , 0 0 1 4} \\
\mathbf{2 , 9 4 9 2 ;} \mathbf{p}^{\mathbf{3}}=\mathbf{0 , 0 0 3 1}\end{array}$ & $\begin{array}{c}15,43(14,41 ; 21,91) \\
0,4192 ; p^{1}=0,6750 \\
0,0676 ; p^{2}=0,9460\end{array}$ & $\begin{array}{c}20,49(14,11 ; 25,63) \\
0,6086 ; p^{1}=0,5427 \\
\mathbf{2 , 1 5 0 4 ;} \mathbf{p}^{2}=\mathbf{0 , 0 3 1 5} \\
1,3066 ; p^{3}=0,1913\end{array}$ \\
\hline BDNF & $\begin{array}{l}44233,38 \\
(38031,63 ; \\
50772,67)\end{array}$ & $\begin{array}{c}33783,10 \\
(27451,64 ; 41849,50) \\
\mathbf{2 , 9 6 1 9 ;} \mathbf{p}^{\mathbf{1}}=\mathbf{0 , 0 0 3 0}\end{array}$ & $\begin{array}{c}39523,96 \\
(35211,51 ; 45794,21) \\
1,5554 ; p^{1}=0,1198 \\
\mathbf{2 , 4 2 6 6} ; \mathbf{p}^{\mathbf{3}}=\mathbf{0 , 0 1 5 2}\end{array}$ & $\begin{array}{c}36217,01 \\
(31859,83 ; 38840,85) \\
\mathbf{2 , 9 3 4 9 ;} \mathbf{p}^{\mathbf{1}}=\mathbf{0 , 0 0 3 3} \\
0,4463 ; \mathrm{p}^{2}=0,6553\end{array}$ & $\begin{array}{c}40902,10 \\
(36849,82 ; 45766,96) \\
1,0955 ; p^{1}=0,2732 \\
0,4192 ; p^{2}=0,6750 \\
\mathbf{2 , 7 9 9 9 ;} \mathbf{p}^{\mathbf{3}}=\mathbf{0 , 0 0 5 1}\end{array}$ \\
\hline CX3CL1 & $\begin{array}{c}2,69 \\
(2,44 ; 3,75)\end{array}$ & $\begin{array}{c}2,62 \\
(2,38 ; 2,86) \\
0,7438 ; \mathrm{p}^{1}=0,4569\end{array}$ & $\begin{array}{c}3,02(2,38 ; 3,78) \\
0,2705 ; p^{1}=0,7867 \\
\mathbf{2 , 2 9 3 8 ;} \mathbf{p}^{\mathbf{3}}=\mathbf{0 , 0 2 1 8}\end{array}$ & $\begin{array}{c}2,76(2,29 ; 3,32) \\
1,1361 ; \mathrm{p}^{1}=0,2559 \\
0,2299 ; \mathrm{p}^{2}=0,8182\end{array}$ & $\begin{array}{c}3,17(2,74 ; 3,75) \\
\mathbf{1 , 9 8 8 1 ;} \mathbf{p}^{\mathbf{1}}=\mathbf{0 , 0 4 6 7} \\
0,9061 ; \mathbf{p}^{2}=0,3648 \\
\mathbf{2 , 0 1 5 9 ;} \mathbf{p}^{\mathbf{3}}=\mathbf{0 , 0 4 3 8}\end{array}$ \\
\hline VEGF & $\begin{array}{c}108,76 \\
(104,15 \\
119,79)\end{array}$ & $\begin{array}{c}112,43 \\
(98,77 ; 130,18) \\
0,0406 ; p^{1}=0,9676\end{array}$ & $\begin{array}{c}120,00 \\
(107,57 ; 135,04) \\
\mathbf{1 , 9 8 8 1 ;} \mathbf{p}^{\mathbf{1}=\mathbf{0 , 0 4 6 7}} \\
\mathbf{2 , 0 9 0 6 ;} \mathbf{p}^{\mathbf{3}}=\mathbf{0 , 0 3 5 6}\end{array}$ & $\begin{array}{c}107,28(93,11 ; \\
127,39) 0,5815 ; \\
\mathrm{p}^{1}=0,56080,6356 ; \\
\mathrm{p}^{2}=0,5249\end{array}$ & $\begin{array}{c}114,16 \\
(101,83 ; 136,93) \\
0,7979 ; p^{1}=0,4248 \\
0,5680 ; p^{2}=0,5700 \\
\mathbf{2 , 3 8 9 2 ;} \mathbf{p}^{\mathbf{3}}=\mathbf{0 , 0 1 6 8}\end{array}$ \\
\hline
\end{tabular}

П р и м е ч а н и е: $\mathrm{p}^{1}-$ уровень значимости различий с группой контроля (критерий Манна-Уитни); $\mathrm{p}^{2}-$ уровень значимости различий между группами «терапия галоперидолом» и «терапия рисперидоном» (критерий Манна-Уитни); $\mathrm{p}^{3}$ - уровень значимости различий между группами «до лечения» и «через 4 недели» (критерий Вилкоксона). Жирным шрифтом выделены статистически значимые результаты. 
По результатам проведенного анализа установлено следующее. Показатели в двух группах больных шизофренией до лечения не различались между собой, что характеризует их как сопоставимые.

Содержание фактора роста нервов ( $\beta$-NGF) у больных обеих групп до лечения было сопоставимо с показателем в группе контроля. Через 4 недели лечения галоперидолом уровень данного нейротрофина увеличился в 1,85 раза ( $\mathrm{p}=0,003)$, значимо превышая показатель как у лиц группы контроля $(\mathrm{p}=0,001)$, так и у пациентов, получающих рисперидон $(\mathrm{p}=0,03)$. При терапии рисперидоном в динамике отмечается только тенденция к росту уровня фактора роста нервов, значимых статистических отличий с группой контроля не получено.

Уровень мозгового нейротрофического фактоpa (BDNF) у пациентов с первым эпизодом шизофрении до лечения был существенно ниже, чем в группе контроля $(\mathrm{p}=0,003)$. Через 4 недели терапии антипсихотиками его содержание существенно увеличилось и стало не отличимым от показателей группы контроля. Зависимости от вида нейролептика установлено не было.

Содержание хемокина CX3CL1 у пациентов с шизофренией при поступлении в стационар не отличалось от такового содержания в группе контроля. Через 4 недели терапии показатель статистически значимо увеличивался $(\mathrm{p}<0,05)$, особенно при приеме рисперидона. Поэтому во 2-й группе больных, получающих рисперидон, величина фракталкина стала значимо отличаться от контроля $(\mathrm{p}<0,05)$.

Уровень васкулоэндотелиального фактора роста (VEGF) у пациентов с шизофренией до лечения не отличался от аналогичного показателя в группе контроля. При терапии антипсихотиками он статистически значимо повышался как в 1-й, так и во 2-й группе $(\mathrm{p}<0,03)$, но особенно у больных, получающих галоперидол, данный показатель стал превышать аналогичный среди здоровых лиц $(\mathrm{p}=0,046)$.

\section{ЗАКЛЮЧЕНИЕ}

Таким образом, полученные результаты свидетельствуют о повышении уровня всех исследуемых показателей нейрорепарации у пациентов с первым эпизодом шизофрении уже на 4-й неделе терапии антипсихотиками, что свидетельствует о раннем включении защитных нейропротективных механизмов и восстановлении мозговой ткани.

При этом уровень мозгового нейротрофического фактора оказался сниженным и постепенно возрастал до контрольных значений в процессе лечения, отличий в зависимости от вида антипсихотика установлено не было. Содержание факто- ра роста нервов и васкулоэндотелиального фактора роста существенно повышалось на фоне терапии галоперидолом, а фракталкина - при терапии рисперидоном.

Полученные результаты свидетельствуют о значительной роли компенсаторной нейрорепарации при шизофрении, которая сохраняется весьма продолжительное время после манифестации острых проявлений психоза. Вероятно, для более глубокого понимания функционирования системы «нейродеструкция - нейрорепарация» при терапии антипсихотиками у больных с первым эпизодом шизофрении необходимы более длительные исследования с оценкой роли показателей нейродеструкции.

\section{КОНФЛИКТ ИНТЕРЕСОВ}

Авторы заявляют об отсутствии возможных конфликтов интересов в связи с публикацией данной статьи.

\section{ИСТОЧНИК ФИНАНСИРОВАНИЯ}

Исследование не имело спонсорской поддержки, выполнено за счет бюджетного финансирования.

\section{СООТВЕТСТВИЕ ПРИНЦИПАМ ЭТИКИ}

Работа соответствует этическим стандартам Хельсинкской Декларации ВМА и одобрена этическим комитетом ФГБОУ ВО «Читинская государственная медицинская академия» Минздрава России (протокол № 100 от 21.02.2020 г.).

\section{ЛИТЕРАТУРА/REFERENCES}

1. Васильева А.И., Говорин Н.В. Нейромаркеры и показатели эндотелиальной дисфункции у пациентов в клинике первого психотического эпизода. Забайкальский медицинский вестник. 2011; 1: 26-32. Vasilieva A.I., Govorin N.V. Neuromarkers and indicators of endothelial dysfunction in patients in the clinic of the first psychotic episode. Transbaikalian Medical Bulletin. 2011; 1: 2632 (in Russian).

2. Гомазков О.А. Нейрогенез как адаптивная функция взрослого мозга. Успехи современной биологии. 2013; 133(4): 349-366. Gomazkov O.A. Neurogenesis as an adaptive function of brain. Advances in Modern Biology. 2013; 133(4): 349-366 (in Russian).

3. Прокопенко С.В., Шанина Е.Г., Петрова М.М., Можейко Е.Ю. Нейрорепарация: современные взгляды на проблему. Фарматека. 2014; 13(286): 20-25. Prokopenko S.V., Shanina E.G., Petrova M.M., Mozheiko E.Yu., Neuroreparation: modern views on the problem. Pharmateca. 2014; 13(286): 20-25 (in Russian).

4. Di Fausto V., Fiore M., Tirassa P., Lambiase A., Aloe L. Eye drop NGF administration promotes the recovery of chemically injured cholinergic neurons of adult mouse forebrain. European Journal of Neuroscience. 2007 October; 26(9): 2473-2480. https://doi.org/10.1111/j.1460-9568.2007.05883.x 
5. Angelucci F., Brenè S., Mathé A.A. BDNF in schizophrenia, depression and corresponding animal models. Mol Psychiatry. 2005 Apr;10(4):34552. doi: 10.1038/sj.mp.4001637

6. Crispoltoni L., Stabile A.M., Pistilli A., Venturelli M., Cerulli G., Fonte C., Smania N., Schena F., Rende M. Changes in Plasma $\beta$-NGF and Its Receptors Expression on Peripheral Blood Monocytes During Alzheimer's Disease Progression. J Alzheimers Dis. 2017;55(3):1005-1017. doi: 10.3233/JAD-160625

7. Меснянкина О.А., Янчевская Е.Ю., Бен М. Фракталкин: патогенетическая роль и диагностические возможности. Кубанский научный медицинский вестник. 2017; 2(163): 148-151. Mesnyankina O.A., Yanchevskaya E.Yu., Ben M. Fractalkin: pathogenetic role and diagnostic capabilities. Kuban Scientific Medical Bulletin. 2017; 2(163): 148-151 (in Russian). https://doi.org/10.25207/1608-6228-2017-2-148-151

8. Fan Q., He W., Gayen M., Benoit M.R., Luo X., Hu X., Yan R. Activated CX3CL1/Smad2 Signals Prevent Neuronal Loss and Alzheimer's Tau Pathology-Mediated Cognitive Dysfunction. J Neurosci. 2020 January [ 29;40(5):1133-1144. doi: 10.1523/JNEUROSCI.1333-19.2019

9. Poniatowski L.A., Wojdasiewicz P., Krawczyk M., Szukiewicz D., Gasik R., Kubaszewski L., Kurkowska-Jastrzębska I. Analysis of the Role of CX3CL1 (Fractalkine) and Its Receptor CX3CR1 in Traumatic Brain and Spinal Cord Injury: Insight into Recent Advances in Actions of Neurochemokine Agents. Mol Neurobiol. 2017 Apr; 54(3):2167-2188. doi: 10.1007/s12035-016-9787-4

10. Verena T., Carsten T. VEGF - A Stimulus for Neuronal Development and Regeneration in the CNS and PNS. Curr Protein Pept Sci. 2018;19(6):589597. doi: 10.2174/1389203719666180104113937

11. Nowacka M.M., Obuchowicz E. Vascular endothelial growth factor (VEGF) and its role in the central nervous system: a new element in the neurotrophic hypothesis of antidepressant drug action. Neuropeptides. $2012 \quad$ February;46(1):1-10. doi: 10.1016/j.npep.2011.05.005

12. Говорин Н.В., Васильева А.И. Влияние галоперидола и рисперидона на нейромаркеры и пока- затели эндотелиальной дисфункции у больных с острой шизофренией. Журнал неврологии и психиатрии им. С.С. Корсакова. 2011; 111(3): 54-57. Govorin N.V., Vasilieva A.I. Effect of haloperidol and risperidone on neuromarkers and indices of endothelial dysfunction in patients with acute schizophrenia. S.S. Korsakov Journal of Neurology and Psychiatry. 2011; 111(3): 54-57 (in Russian).

13. Huang T.L. Effects of antipsychotics on the BDNF in schizophrenia. Curr Med Chem. 2013;20(3):34550. doi: 10.2174/092986713804870729

14. Libman-Sokołowska M., Drozdowicz E., Nasierowski T. BDNF as a biomarker in the course and treatment of schizophrenia. Psychiatr Pol. 2015;49(6):1149-58. doi: 10.12740/PP/37705

15. Man L., Lv X., Du X., Yin G., Zhu X., Zhang Y., Soares J., Yang X., Chen X., Zhang X. Cognitive impairments and low BDNF serum levels in firstepisode drug-naive patients with schizophrenia. Psychiatry Res. $2018 \quad$ May;263:1-6. doi: 10.1016/j.psychres.2018.02.034

16. Arabska J., Margulska A., Strzelecki D., Wysokiński A. Does metabolic status affect serum levels of BDNF and MMP-9 in patients with schizophrenia? Nord J Psychiatry. 2019 Nov;73(8):515521. doi: 10.1080/08039488.2019.1658126

17. Qin X., Wu H., Cao C., Loh Y., Cheng Y. A metaanalysis of peripheral blood nerve growth factor levels in patients with schizophrenia. Mol Psychiatry.2017 Sep;22(9):1306-1312. doi: $10.1038 / \mathrm{mp} .2016 .235$

18. Hill S.L., Shao L., Beasley C.L. Diminished levels of the chemokine fractalkine in post-mortem prefrontal cortex in schizophrenia but not bipolar disorder. World J Biol Psychiatry. 2020 May 21;1-10. doi: 10.1080/15622975.2020.1755451

19. Zhou H., Wang J., Zhang Y., Shao F., Wang W. The Role of Microglial CX3CR1 in SchizophreniaRelated Behaviors Induced by Social Isolation. Frontiers in Integrative Neuroscience. 2020; 14: 551676. https://doi.org/10.3389/fnint.2020.551676

Поступила в редакцию 28.08.2020 Утверждена к печати 30.11.2020

Сахаров Анатолий Васильевич - д.м.н., доцент, первый проректор, заведующий кафедрой психиатрии, наркологии и медицинской психологии. Author ID РИНЦ 556868. Author ID Scopus 57201327574. Researcher ID WOS: N-4261-2016.

Мындускин Иван Владимирович - врач-психиатр, аспирант кафедры психиатрии, наркологии и медицинской психологии.

Терешков Павел Петрович - к.м.н., заведующий лабораторией клинической и экспериментальной биохимии и иммунологии НИИ молекулярной медицины.

Сахаров Анатолий Васильевич, sawt@list.ru 
UDC 616.895.87-056.34:340.631.4: 616-008.811.9:615.015.44:615.214

For citation: Sakharov A.V., Mynduskin I.V., Tereshkov P.P. Indicators of neuro-repair in patients with the first episode of schizophrenia during antipsychotic therapy. Siberian Herald of Psychiatry and Addiction Psychiatry. $2020 ; 4$ (109): 15-20. https://doi.org/10.26617/1810-3111-2020-4(109)-15-20

\title{
Indicators of neuro-repair in patients with the first episode of schizophrenia during antipsychotic therapy
}

\section{Sakharov A.V.', Mynduskin I.V.1, 2, Tereshkov P.P.'1}

${ }^{1}$ Chita State Medical Academy

672090, Gorky Street 39A, Chita, Russian Federation

${ }^{2}$ Regional Clinical Psychiatric Hospital named after V.Kh. Kandinsky

672042, District Passage no. 3, Chita, Russian Federation

\begin{abstract}
Introduction. Currently, there is no doubt about the essential role of the processes of neurodestruction and neuroreparation in the mechanisms of development of mental disorders, including schizophrenia. At the same time, many neurotrophic factors remain unexplored in this disease, including their dynamics against the background of antipsychotic therapy. Objective: to study some indicators of neuroreparation in patients with the first episode of schizophrenia during therapy with first- and second-generation antipsychotics. Materials and Methods. We examined 40 patients with a diagnosis of "paranoid schizophrenia, follow-up period less than a year" (F20.09), the examination was carried out twice: before the start of treatment with antipsychotics and after 4 weeks of psycho-pharmacotherapy. Patients of the first group received haloperidol, the second group - risperidone. The control group consisted of 20 healthy volunteers. Neuromarker parameters were determined in blood serum by flow fluorimetry. Results. The level of brain neurotrophic factor was reduced and gradually increased to control values during treatment; no differences were found depending on the type of antipsychotic. The content of nerve growth factor and vasculoendothelial growth factor significantly increased with haloperidol therapy, and fractalkine - with risperidone therapy. Thus, an increase in the level of all studied parameters of neuroreparation in patients with the first episode of schizophrenia was found, which indicates the early activation of neuroprotective mechanisms during antipsychotic therapy.
\end{abstract}

Keywords: schizophrenia, antipsychotics, neuroreparation, nerve growth factor, brain neurotrophic factor, fractalkine, vasculoendothelial growth factor.

Received August 28.2020

Accepted November 30.2020

Sakharov Anatoly V. - MD, associate professor, first vice-rector, Head of the Department of Psychiatry, Narcology and Medical Psychology, Chita, Russian Federation. Author ID RSCI 556868. Author ID Scopus 57201327574. Researcher ID WOS: N-4261-2016.

Mynduskin Ivan V. - psychiatrist, postgraduate of the Department of Psychiatry, Narcology and Medical Psychology, Chita, Russian Federation.

Tereshkov Pavel P. - PhD, Head of the Laboratory of Clinical and Experimental Biochemistry and Immunology, Research Institute of Molecular Medicine, Chita, Russian Federation.

Sakharov Anatoly V., sawt@list.ru 